\title{
Text Antenna based on Meander Line for RFID Integrated Circuit Transponders
}

\author{
G. M. Cipullo, H. X Araujo, I. R. S. Casella, and C. E. Capovilla
}

\begin{abstract}
In this work, a text antenna based on a meandershape dipole structure is proposed. The use of text antennas can bring interesting technological advantages in terms of advertising, marketing and logistics. The proposed planar antenna operates at UHF band and its shape is designed to represent the name of the Universidade Federal do ABC (i.e. Federal do ABC - UFABC), The performance of the antenna is evaluated by simulation and by measurements in a built prototype, considering its input return loss and radiation pattern characteristics. The obtained results show the viability of using the proposed antenna in RFID integrated circuit transponders.
\end{abstract}

Index Terms-Planar antennas, dipole antennas, meander lines, RFID integrated circuit.

\section{INTRODUCTION}

The wireless remote sensor applications have become a great source of knowledge and technological innovations. The Radio Frequency IDentification (RFID) has been used on a large scale, and now, has become an important tool applied in logistics operations. In RFID systems, data are transferred between a wireless transponder (tag) and a reading unit [1]. Due to its simple structure, RFID tags are directly attached to the element to be identified (e.g. components, pallets, containers, vehicles, machinery, and services) [2].

The transponders can be active or passive. The passive ones represent a good combination of cost and performance [3], [4]. Typically, a passive RFID transponder is made up of an Application-Specific Integrated Circuit (ASIC) and an antenna [4]. The antenna of the transponder, usually planar, is an important part of the system to guarantee the quality of the wireless communication link. Its specs must comply with some international standards, providing compatibility and interoperability between the different components involved in the system [5].

The RFID antennas, operating in the Ultra High Frequency (UHF) band, can assume different shapes, depending on its application [6], [7]. However, in general, they are designed to be omnidirectional [5], [8]. One interesting class of antennas that can be used for RFID applications is the meander line antennas [9], [10]. They were proposed in [11] as an attempt to reduce the physical size of the antenna by folding the antenna in sections, so that, its resonant frequency is reduced when compared with a similar one of the same physical length [12].

G. M. Cipullo, I. R. S. Casella, and C. E. Capovilla are with the Universidade Federal do ABC - UFABC, Brazil. E-mails: monacelli.cipullo@aluno.ufabc.edu.br, ivan.casella@ufabc.edu.br, and carlos.capovilla@ufabc.edu.br

H. X Araujo is with the Universidade Federal de Sao Joao del Rei - UFSJ, Brazil. E-mail: hxaraujo@ufsj.edu.br
In Figure 1, a dipole antenna is shown in meander line shape (six sections), with distance between the adjacent lines equal to its width, in this way, assuring a symmetrical structure to the antenna. If a conventional dipole presents size $L$ and the dipole in a meander shape presents size $l$, the reduction factor $\beta$ is equal to $\beta=l / L$, usually, in the order of 24 to $40 \%$ [11]. Due to its folded shape, the capacitance and inductance per unit length are increased, reducing the propagation speed in the meander and, consequently, providing a reduction of the necessary physical length of the antenna, when compared to an original dipole (for the same performance).

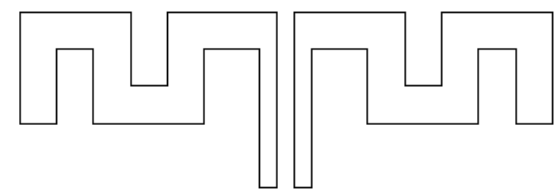

Figure 1: Meander line as a dipole antenna.

In this context, we propose in this paper, the design of a planar text antenna for RFID applications, operating in the range of $900 \mathrm{MHz}$ to $940 \mathrm{MHz}$ (UHF band), based on a meander line structure that represents the name of the Universidade Federal do ABC. The paper is organized as follows: besides this introductory section, proposed text antenna is shown in section II; main analysis and main results are considered in section III; and section IV concludes the work.

\section{Proposed text Antenna}

Among several options of antennas available for RFID applications, the use of text format antennas is quite unique [13] since they are based on non-uniform meander lines. In other words, they consist on a thin line modeled of different ways to reproduce the shape of letters. Brand names or logos can be used to make the radiating element for RFID tags, which gives an additional value to their tags as a high-tech advertising [1].

The proposed antenna, presented in Figure 2, was designed on a FR-4 substrate $\left(\varepsilon_{r}=4,4, \delta=0,018\right.$ and $\left.h=1,6 \mathrm{~mm}\right)$. It was chosen due to its easy acquisition and low cost prototyping [14].

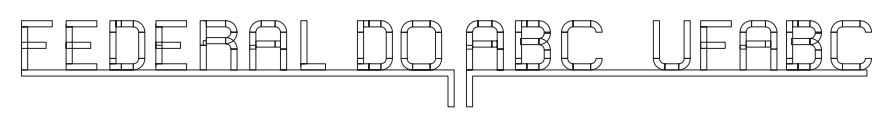

Figure 2: Proposed text antenna (98 x $6.5 \mathrm{~mm})$. 
As shown in Figure 2, the text "FEDERAL DO ABC UFABC" is in contact with a straight dipole structure underneath the letters. The axial length of the conventional halfwave dipole having the resonant frequency of $920 \mathrm{MHz}$ is $\lambda_{g}$ $=128 \mathrm{~mm}$ and the line thickness is around $1 \mathrm{~mm}$ for a optimal impedance matching. The text and letters were designed to maintain the line thickness and axial length proportions.

\section{AnAlysis of Results}

The simulations were performed using the Method of Moments (MoM), taking into account all the required boundary conditions (lack of ground plane, substrate with finite dimensions, and differential input signal), with the aid of the momentum package, a computational tools of the Agilent Advanced Design System (ADS). In order to optimize the prototype, an iterative process was used. The letters spacing, line thickness, and axial length were optimized for the desired frequency range between 900 and $940 \mathrm{MHz}$. The optimized axial length is $98 \mathrm{~mm}$, a reduction of $24 \%$ in comparison with the half-wave dipole. This size reduction is due to the meander shape that the letters have applied to the antenna structure.

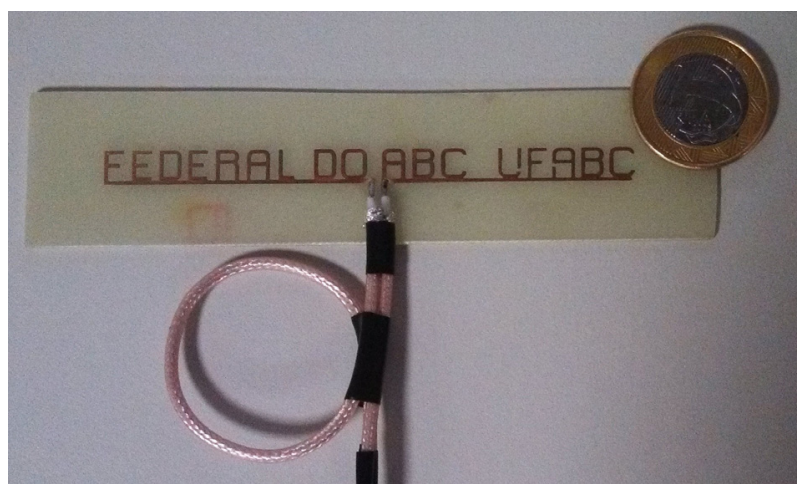

Figure 3: Photography of the built antenna.

The connection between the antenna and the network analyzer was performed by a balun (balanced-unbalanced), which was designed with RG316 coaxial cable. The built antenna (with its respective balun) is shown in Figure 3. The ratio of the balun is $1: 1$, where the length of the loop is $3 / 4$ of guided wavelength and the length of the parallel line is $1 / 4$.

In general, the nominal permittivity value of the substrate is not accurate enough for the design of planar antennas. Thus, simulations were performed based on corner analysis, showing the results of the input return loss for $\varepsilon_{r}=4.0$ and $\varepsilon_{r}=4.8$, besides the typical one.

In Figure 4 is shown the input return loss of the antenna. In order to ensure the full functionality of the prototype, the adopted criterion to analyze the bandwidth was the usual value of VSWR 2:1 or VSWR $\leq 2$, since in this range at least $90 \%$ of the antenna input power will be radiated [15]. This assumption is equivalent to reach $S_{11} \leq-10 \mathrm{~dB}$.

It can be noted that the simulated and measured results are in complete agreement with the resonance frequency of $920 \mathrm{MHz}$, showing that, for this prototype, $\varepsilon_{r}$ is tending to the typical value. For this value of $\varepsilon_{r}$, the simulated bandwidth is around
$7.5 \%$ (888 MHz to $957 \mathrm{MHz}$ ), while the measured one is $4 \%$ (900MHz to $937 \mathrm{MHz}$ ).

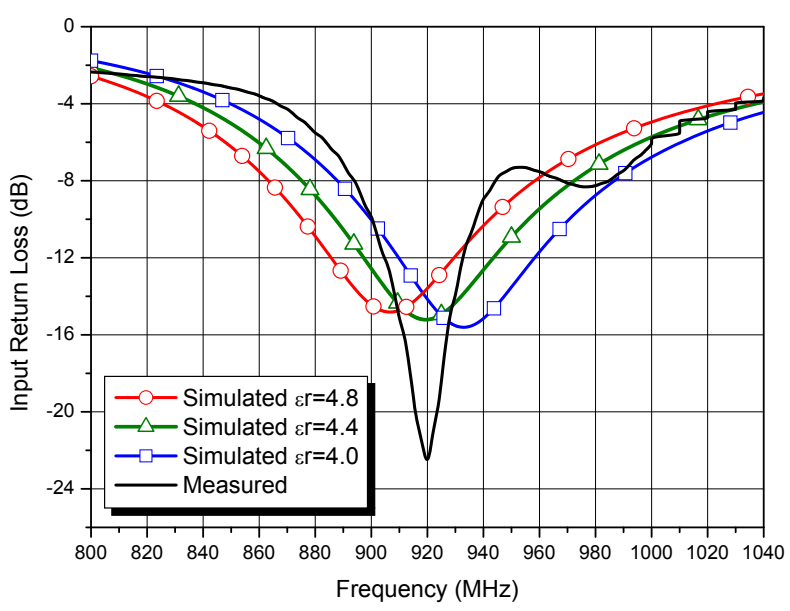

Figure 4: Simulated and measured results of antenna input return loss.

The reduction of the measured bandwidth is caused by the intrinsic characteristics of the employed balun $(50 \Omega$ coaxial cable). As the balun is just a necessary device for performing the measurements, it was not taken into account in the simulations.

For connecting the antenna to a real chip tag, an appropriated impedance matching circuit should be adopted. In general, chip tag input impedance is very capacitive (around $10-j 200 \Omega$ at $920 \mathrm{MHz}$ ). Thus, a loading bar can be added and adjusted to obtain optimum inductive reactance and resistance matching. The trimming can be also easily obtained by punching holes through the antenna trace at defined locations or by lumped elements.

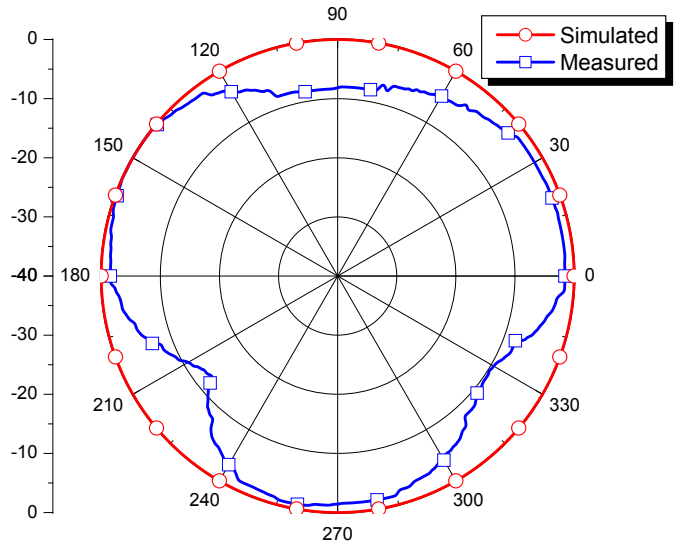

Figure 5: Simulated and measured antenna results of E-CoPol radiation pattern at $920 \mathrm{MHz}$.

In Figures 5 and 6 are presented the simulation and measurement results of the E-Plane and H-Plane radiation patterns, respectively, for the antenna at $920 \mathrm{MHz}$ (normalized). Through the analysis of the radiation pattern, it can be observed that the antenna is linearly polarized, with the E plane (E-CoPol) predominant at the substrate, and the $\mathrm{H}$ plane $(\mathrm{H}-\mathrm{CoPol})$ normal to the substrate. 


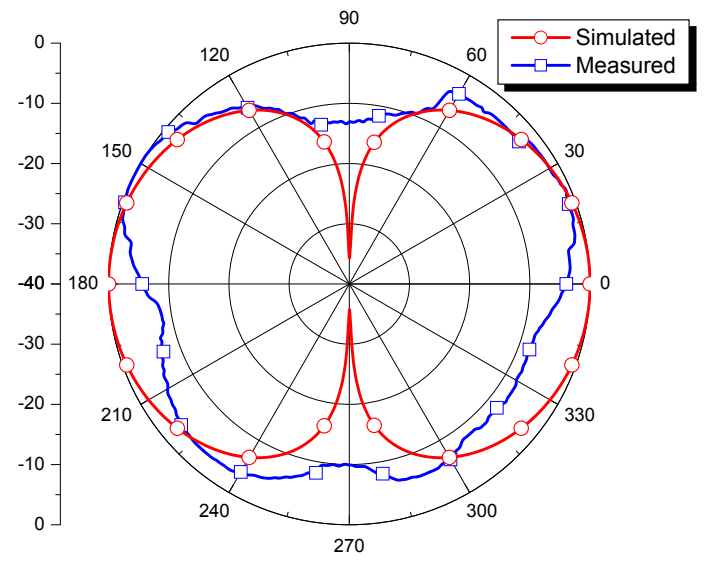

Figure 6: Simulated and measured antenna results of $\mathrm{H}-\mathrm{CoPol}$ radiation pattern at $920 \mathrm{MHz}$.

The simulated radiation pattern results are in agreement with the measured ones, showing the efficacy and ensuring the functionality of the prototype. The cross polarization fields (EXpol and $\mathrm{H}-\mathrm{Xpol}$ ) are at least $25 \mathrm{~dB}$ below, ensuring a good purity for the linear polarization of the antenna.

Completing the radiation pattern analysis, it is presented in Figure 7 the measured 3D antenna pattern. The resulting pattern looks kind of like a nonhomogeneous bagel radiating energy outward. The strongest energy is radiated outward, perpendicular to the antenna in the $\mathrm{x}-\mathrm{y}$ plane.
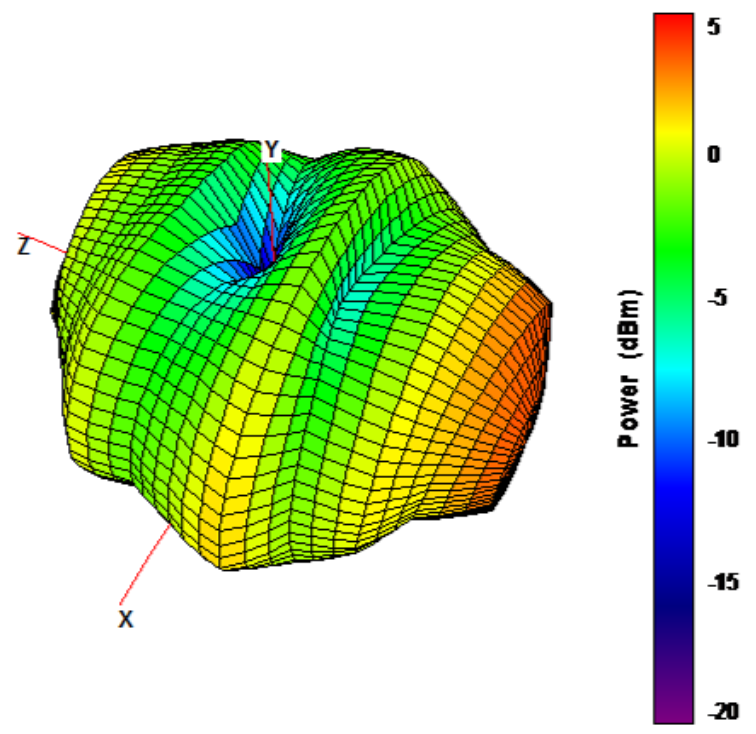

Figure 7: Measured antenna results of 3D radiation pattern at $920 \mathrm{MHz}$.

This nonhomogeneous behavior is due to the letters of the dipole as a text line meander. Notice that the patterns in any orthogonal plane (any plane, actually) are directional, and so, this antenna meets an omnidirectional behavior. Besides, it can be seen that the antenna has quasi-omnidirectional behavior, which evidences and ensures its good behavior as a radiator element for RFID transponders. These results demonstrate that the antenna keeps the good characteristics of a traditional dipole, even on the meander shape.
As illustrated in Figures 8 and 9, the 3D radiation pattern measurements were performed in the anechoic chamber $(7.6 \mathrm{~m}$ $\mathrm{x} 3.1 \mathrm{~m} \mathrm{x} 3.1 \mathrm{~m}$ ) installed inside the Laboratory of Information and Communication (LIC) at UFABC. This chamber was fabricated by ETS-Lindgren (Spacesaver H26 Model - up to $18 \mathrm{GHz}$ ) with Rodhe \& Schwarz equipments. Both, the transmitting horn antenna (EQ3117 Model) and the prototype, were positioned inside the quiet zone, defined as an imaginary sphere where the antennas must be placed inside to guarantee that the level of the reflected signal is less than $30 \mathrm{~dB}$ [16]. Also, in this chamber, the electromagnetic field uniformity is less than $6 \mathrm{~dB}$ and the normalized site attenuation is less than $+/-4 \mathrm{~dB}$ in the range from $1 \mathrm{GHz}$ to $18 \mathrm{GHz}$.

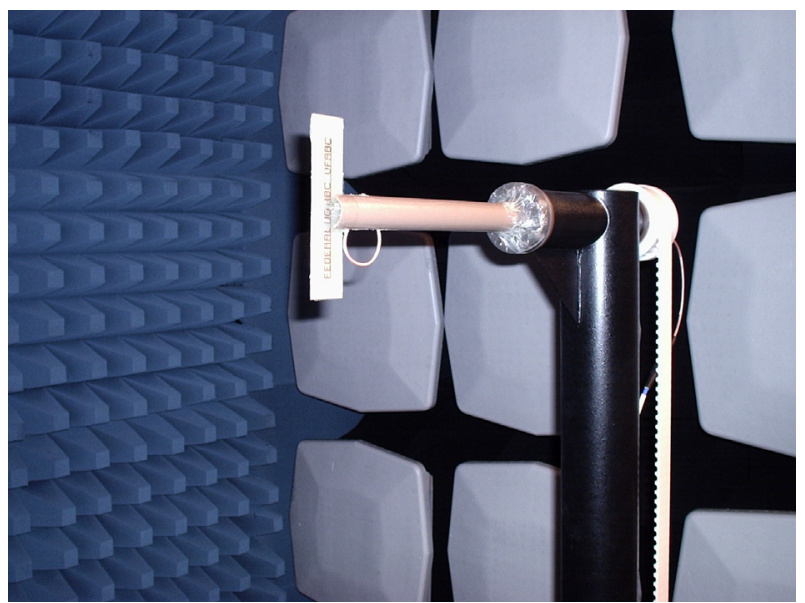

Figure 8: Prototype connected to the turntable.

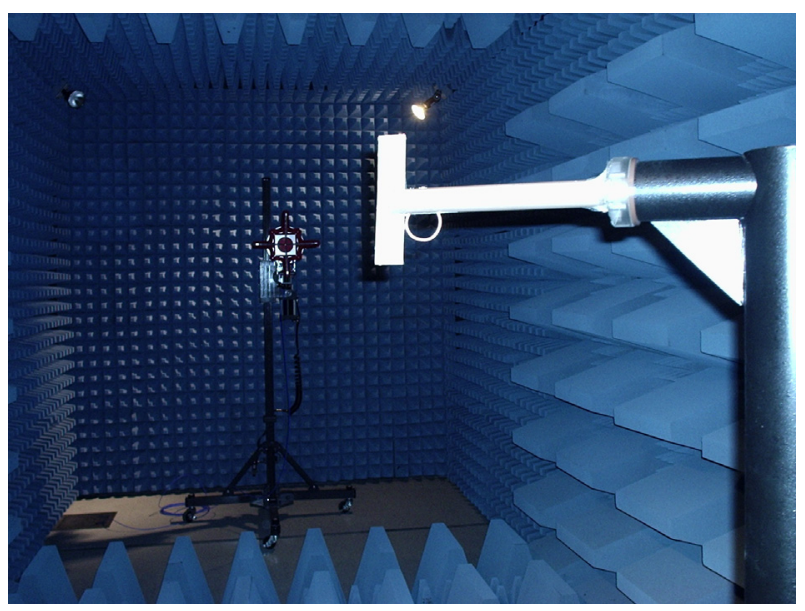

Figure 9: Text antenna at UFABC anechoic chamber.

Finally, it is also important to characterize the antenna gain and efficiency. The simulated results of the gain and efficiency are, respectively, $2.15 \mathrm{dBi}$ and $90 \%$. In this way, the obtained results show that the proposed antenna can perfectly operate in RFID devices, allowing the compatibility with monolithic integration through chip-on-board technique with direct connection between the planar antenna and the IC for the tag construction. 


\section{CONCLUSION}

This work proposes a planar meander antenna in the shape of text for RFID applications. The antenna presents a visual attractive, combining marketing values with operational capabilities. The antenna can be employed in almost all products inside a production chain due to its planar characteristic. The presented text antenna showed satisfactory results, both simulated and measured at $920 \mathrm{MHz}$ with a bandwidth around $40 \mathrm{MHz}$. Regarding to the radiation pattern, its behavior is quasi-omnidirectional, like a normal dipole, for both $\mathrm{E}$ and $\mathrm{H}$ planes. In this context, the proposed text antenna is fully operational for low cost RFID applications and is suitable for transponders with needs or desires a marketing appeal in UHF band.

\section{REFERENCES}

[1] A. M. A. Salama, Antennas of RFID Tags. In-Tech, 2010.

[2] C. Y. Lin, "An empirical study on organizational determinants of RFID adoption in the logistics industry," Journal of Technology Management \& Innovation, vol. 04, pp. 01-07, 2009.

[3] E. DiGiampaolo and F. Martinelli, "Mobile robot localization using the phase of passive UHF RFID signals," IEEE Transactions on Industrial Electronics, vol. 61, pp. 365-376, 2014.

[4] K. V. S. Rao, P. V. Nikitil, and S. F. Lam, "Antenna design for UHF RFID tags: A review and a practical application," IEEE Transactions on Antennas and Propagation, vol. 53, pp. 3870-3876, 2005.

[5] K. Finkenzeller, RFID Handbook. John Wiley \& Sons, 2003.

[6] G. Marrocco, "The art of UHF RFID antenna design: impedancematching and size-reduction techniques," IEEE Antennas and Propagation Magazine, vol. 50, no. 01, pp. 66-79, 2008.

[7] E. Perret, S. Tedjini, and R. S. Nair, "Design of antennas for UHF RFID tags," Proceedings of the IEEE, vol. 100, no. 07, pp. 2330-2340, 2012.

[8] C. A. Balanis, Antenna Theory: Analysis and Design, 2nd ed. John Wiley \& Sons, 1997.

[9] C. Calabrese and G. Marrocco, "Meandered-slot antennas for sensorRFID tags," IEEE Antenas and Wireless Propagation Letters, vol. 07, pp. 05-09, 2008.

[10] O. O. Olaode, W. D. Palmer, and W. T. Joines, "Effects of meandering on dipole antenna resonant frequency," IEEE Antenas and Wireless Propagation Letters, vol. 11, pp. 122-125, 2012.

[11] J. Rashed and C.-T. Tai, "A new class of resonant antennas," IEEE Transactions on Antennas and Propagation, vol. 39, pp. 1428-1430, September 1991.

[12] Y. Sato and T. Fukusako, "Low-profile and electrically small meanderline antenna using a capacitive feed structure," IEEE Antenas and Wireless Propagation Letters, vol. 11, pp. 1281-1284, 2012.

[13] M. Keskilammi and M. Kivikoski, "Using text as a meander line for RFID transponder antennas," IEEE Antenas and Wireless Propagation Letters, vol. 03, pp. 372-374, 2004.

[14] L. C. Kretly and C. E. Capovilla, "A novel antenna array based on quasi-yagi element for adaptive wireless system applications," IEEE International Microwave and Optoelectronics Conference, vol. 01, pp. 307-312, September 2003.

[15] P. Salonen, L. Sydänheimo, M.Keskilammi, and M. Kivikoski, "A small planar inverted-f antenna for wearable applications," The Third International Symposium, pp. 95-100, 1999.

[16] H. Arai, Measurement of a Mobile Antenna Systems. Artech House, 2001.

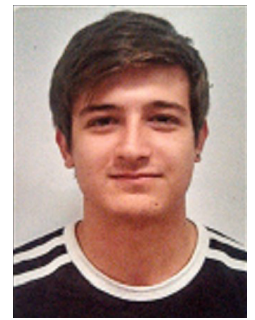

Guilherme Monacelli Cipullo was born in São Paulo, Brazil, in 1994. He's a graduating on Science and Technology at Federal University of ABC (UFABC), in Santo André, São Paulo, Brazil. He started with research activities since 2012, when he got into the university. His first activities includes devices for communication systems, more specifically antennas used in RFID.

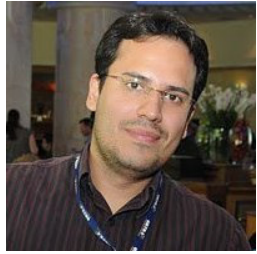

Humberto Xavier de Araujo received his Ph.D from University of Campinas in 2012. His field of interest includes Electromagnetic Compatibility, metamaterials, analog integrated circuits, active microwave devices and antennas. He has expertise on the design and development of setups for EMI/EMS measurements, and metamaterials prototypes. Nowadays, he is with the Federal University of São João Del Rei, as Professor of the Telecommunications Engineering.

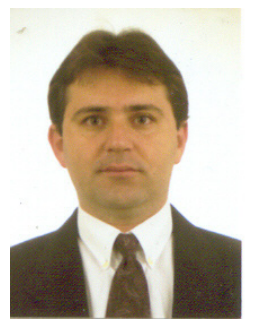

Ivan Roberto Santana Casella received his M.S. and $\mathrm{PhD}$. in Electrical Engineering from the Polytechnic School of the University of Sao Paulo (EPUSP). Part of his PhD was developed at the University of Toronto (UofT) in Canada, where he acted as researcher and teacher assistant. He worked as electronic designer at the Consumer Electronics Development Laboratories of Philips and as researcher at the Automation and Informatics Research and Development Center of NEC (CPDIA) in the design and analysis of analog and digital systems. He is now Adjunct Professor IV at the Federal University of ABC (UFABC) and chair of the Communication and Information Laboratory (LIC). His current interests are in the areas of wireless communication and smart grid.

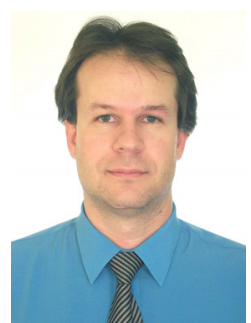

Carlos Eduardo Capovilla was born in Vinhedo, Brazil, on March 06, 1977. He received the B.S. degree from the University of Sao Paulo in 2001, M.Sc. and Ph.D. degrees from the University of Campinas in 2004 and 2008, all in Electrical Engineering - RF Microelectronics. He is currently a Professor with the Federal University of ABC (UFABC). His current research interests include RF CMOS integrated circuits, smart antennas, mobile systems design, smart grid applications, and telecommunications in complex environments. 